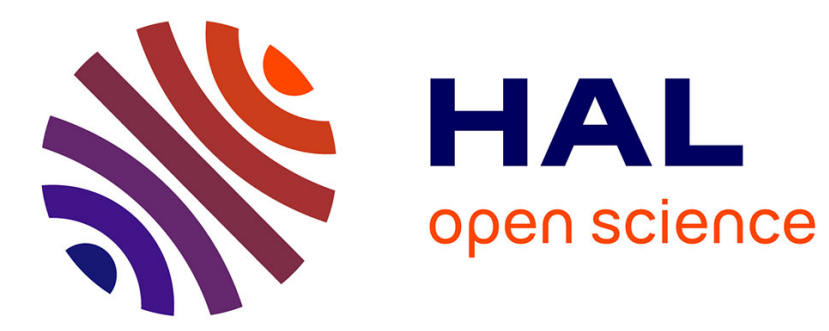

\title{
Efficient reluctance network formulation for modeling design and optimization of linear hybrid motor
}

E. Manaa Barhoumi, Frédéric Wurtz, Christian Chillet, Boubker Bensalah, Olivier Chadebec

\section{- To cite this version:}

E. Manaa Barhoumi, Frédéric Wurtz, Christian Chillet, Boubker Bensalah, Olivier Chadebec. Efficient reluctance network formulation for modeling design and optimization of linear hybrid motor. IEEE Transactions on Magnetics, 2016, 52 (3), 10.1109/TMAG.2015.2496730 . hal-01385558

\section{HAL Id: hal-01385558 \\ https://hal.science/hal-01385558}

Submitted on 23 Nov 2020

HAL is a multi-disciplinary open access archive for the deposit and dissemination of scientific research documents, whether they are published or not. The documents may come from teaching and research institutions in France or abroad, or from public or private research centers.
L'archive ouverte pluridisciplinaire HAL, est destinée au dépôt et à la diffusion de documents scientifiques de niveau recherche, publiés ou non, émanant des établissements d'enseignement et de recherche français ou étrangers, des laboratoires publics ou privés. 


\title{
Efficient Reluctance Network Formulation for Modeling Design and Optimization of Linear Hybrid Motor
}

\author{
E. M. Barhoumi ${ }^{1,2,3}$, F. Wurtz ${ }^{3}$, Member, IEEE, C. Chillet $^{3}$, \\ B. Ben Salah ${ }^{1}$, and O. Chadebec ${ }^{3}$ \\ ${ }^{1}$ National Engineering School of Tunis, University of Tunis El Manar, Tunis 1002, Tunisia \\ ${ }^{2}$ College of Engineering, Majmaah University, Al Majmaah 11952, Saudi Arabia \\ ${ }^{3}$ Univ. Grenoble Alpes, G2Elab, F-38000 Grenoble, France \\ CNRS, G2Elab, F-38000 Grenoble, France
}

\begin{abstract}
The aim of this paper is to propose an efficient and unique reluctance network (RN) model for all translator displacements of a linear hybrid motor. This model has to consider several translator positions to analyze the linear motor performances. The proposed RN model takes into account the magnetic characteristic and the flux leakage. Consequently, the proposed model gives precise results of the electromagnetic characteristic. The RN model considers an interesting solution to deal quickly with an optimization task of a large number of constraints and parameters. The developed model is coupled with sequential quadrating programming method for an optimization process of the linear machine. The obtained results confirm the efficiency of this method for modeling and optimization of the linear machine.
\end{abstract}

Index Terms - Electromagnetic analysis, magnetic flux, magnetic forces, optimization, reluctance network (RN).

\section{INTRODUCTION}

$\mathbf{T}$ HE LINEAR hybrid motors (LHMs) consist of an efficient solution for precise linear displacements applications [1]. Many research papers work on the design and the optimization of these machines [2]. The finite element method (FEM) is generally used when precise results are indispensable [3]. However, this method needs large computation time, limiting the number of parameters that can be taken into account. Moreover, the FEM cannot be coupled with rapid optimization algorithms [4]. The second method used in the design of linear machines is based on the reluctance network (RN) model [3]-[5]. In this paper, we are concerned with the development of a new RN model for modeling and optimization of linear machines. A 3-D view of the studied machine is shown in Fig. 1. The main dimensions of the proposed LHM are shown in Fig. 2.

The double-sided LHM mechanical dimensions are summarized in Table I.

In Section II, a unique RN model for all translator positions is presented and discussed. The comparison of results with that of the FEM is presented in Section III. The optimization of the machine is presented and discussed in Section IV. The optimization task consists in reducing the global mass of the machine. The electromagnetic characteristics of the optimized structure are also presented and verified using the FEM. The conclusions and perspectives are given in Section V.

\section{Unique Reluctance Network Model FOR ALl DisPlacements}

The concept is based on the subdivision of the magnetic circuit of the machine into a sufficient number of elements

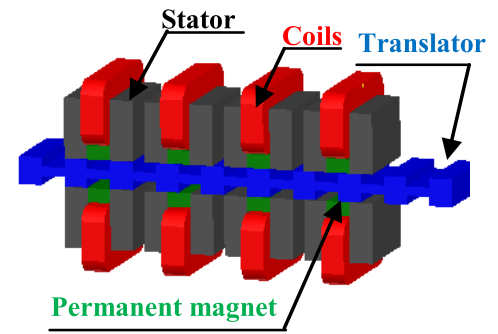

Fig. 1. Double-sided hybrid motor.

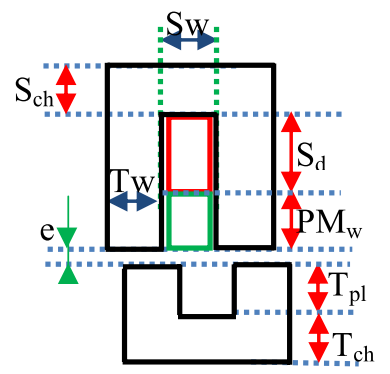

Fig. 2. Geometrical dimensions.

TABLE I

LHM DESIGN SPECIFICATIONS

\begin{tabular}{lll}
\hline \hline \multicolumn{1}{c}{ Quantity } & \multicolumn{1}{c}{ Symbol } & \multicolumn{1}{c}{ Values } \\
\hline Tooth width & $\mathrm{Tw}$ & $50 \mathrm{~mm}$ \\
Air gap width & $\mathrm{e}$ & $1 \mathrm{~mm}$ \\
Translator thickness & $\mathrm{Tt}$ & $200 \mathrm{~mm}$ \\
Translator pole length & $\mathrm{Tpl}$ & $20 \mathrm{~mm}$ \\
Translator cylinder head & $\mathrm{Tch}$ & $20 \mathrm{~mm}$ \\
Current excitation & $\mathrm{I}$ & $6 \mathrm{~A}$ \\
Turns per phase & $\mathrm{N}$ & 1500 \\
\hline \hline
\end{tabular}

known as flux tubes. Each flux tube is associated with a magnetic reluctance, which depends on circuit dimension and the magnetic behavior. The originality of this model consists 


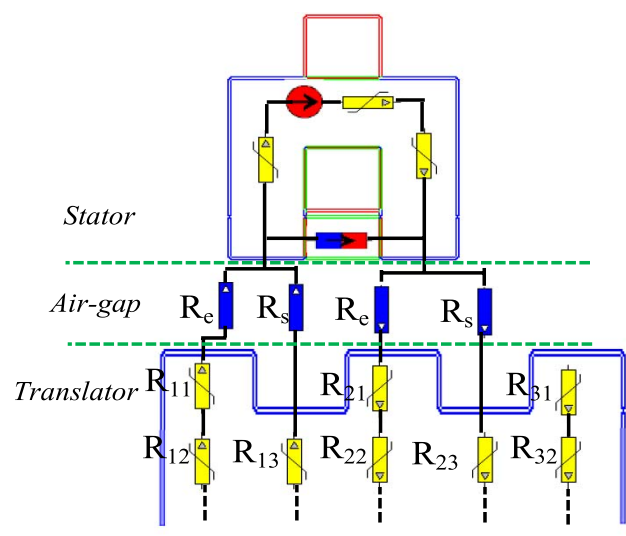

Saturable iron reluctance Permanent magnet reluctance Air gap reluctance Magnetomotive force

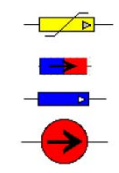

Fig. 3. Construction of the RN.

in its ability to calculate the electromagnetic characteristics for various positions from unaligned to aligned positions using a simple run and a unique topology of model. An elementary structure of the LHM with the respective reluctances is shown in Fig. 3.

\section{A. Reluctances of the Air Gap}

The air gap flux tubes are composed of straight lines with a constant length. However, the section of the air gap increases with the displacement $x$. Hence, the air gap reluctance is parameterized with the displacement, and it is given by the following expression:

$$
\Re_{e}=\frac{e}{\mu_{0} \cdot x \cdot \mathrm{Tt}} .
$$

The salient in the mobile canalizes a non-neglected part of the magnetic flux. Hence, the salient is modeled by reluctances expressed as follows:

$$
\mathfrak{R}_{s}=\frac{\mathrm{Tpl}+e}{\mu_{0} \cdot(\mathrm{Tw}-x) \cdot \mathrm{Tt}} .
$$

\section{B. Reluctances of the Stator}

Generally, the magnetic reluctance of a ferromagnetic material, with a length $l$ and a section $S$, can be written as

$$
\Re_{\mathrm{fer}}=\frac{l}{\mu_{0} \cdot \mu_{r} \cdot S}
$$

$\mu_{r}$ is the relative permeability, which depends on the saturation of the ferromagnetic material. Hence, the ferromagnetic circuit of stator is divided into three different magnetic reluctances connected in series. These reluctances depend on both the stator geometrical parameters and the magnetic permeability.

\section{Reluctances of the Permanent Magnet}

Each permanent magnet inserted in the stator is modeled by a magnetomotive force and a reluctance parametrized with the geometrical and magnetic parameters of the permanent magnet. This magnetomotive force and the reluctance of the permanent magnet can be written, respectively, as

$$
\begin{aligned}
E_{a} & =\frac{B_{r}}{\mu_{0} \cdot \mu_{a}} L_{a} \\
\Re_{a} & =\frac{1}{\mu_{0} \cdot \mu_{a}} \frac{L_{a}}{S_{a}}
\end{aligned}
$$

where $\mu_{a}$ is the relative magnetic permeability of the permanent magnet. $L_{a}$ and $S_{a}$ are, respectively, the length and the section.

\section{Reluctances of the Translator Part}

The translator part is moved from unaligned to aligned positions. Consequently, the translator canalizes different flux tubes, which depend on the translator position. The RN model developed must be available for each translator position. Hence, the translator part is modeled by different reluctances. The flux in the second translator teeth, which must be aligned with those of the stator in the aligned position, increases with the displacement. Hence the reluctance of the teeth is inversely proportional to the displacement, and it can be written as

$$
\Re_{21}=\frac{\mathrm{Tpl}}{\mu_{0} \cdot \mu_{r} \cdot x \cdot \mathrm{Tt}} .
$$

Applying the same methodology, the reluctances of other parts are determined. The reluctances $\Re_{11}$ and $\Re_{31}$ are, respectively, given as

$$
\begin{aligned}
\Re_{11} & =\frac{\mathrm{Tpl}}{\mu_{0} \cdot \mu_{r} \cdot \mathrm{Tw} \cdot \mathrm{Tt}} \\
\Re_{31} & =\frac{\mathrm{Tpl}}{\mu_{0} \cdot \mu_{r} \cdot \frac{(\mathrm{Tw}-x)}{2} \cdot \mathrm{Tt}} .
\end{aligned}
$$

The reluctances of the cylinder head depend on both the teeth position and the displacement. The reluctances $\Re_{12}, \Re_{13}$ and $\Re_{22}$ are, respectively, given as

$$
\begin{aligned}
\Re_{12} & =\frac{\mathrm{Tch}}{\mu_{0} \cdot \mu_{r} \cdot \mathrm{Tw} \cdot \mathrm{Tt}} \\
\mathfrak{R}_{13} & =\frac{\mathrm{Tch}}{\mu_{0} \cdot \mu_{r} \cdot \frac{(\mathrm{Tw}-x)}{2} \cdot \mathrm{Tt}} \\
\mathfrak{R}_{22} & =\frac{\mathrm{Tch}}{\mu_{0} \cdot \mu_{r} \cdot x \cdot \mathrm{Tt}} .
\end{aligned}
$$

The reluctances $\Re_{23}$ and $\Re_{32}$ are, respectively, given as

$$
\Re_{23}=\Re_{32}=\frac{\mathrm{Tch}}{\mu_{0} \cdot \mu_{r} \cdot \frac{(\mathrm{Tw}-x)}{2} \cdot \mathrm{Tt}} .
$$

\section{E. Reluctances of the Leakage Flux}

The RN model developed in this paper has two advantages. Firstly, both flux leakages between the stator and the translator on one part and on the stator on the other are considered and represented by the circumference arcs. This leakage flux strongly influences the flux with a considerable effect on the magnetic field in this actuator. In fact, $\mathrm{RN}$ simulation results obtained by neglecting the leakage flux lead to important errors compared with the FEM. Secondly, the flux leakage reluctances vary with the translator displacement. The leakage flux 


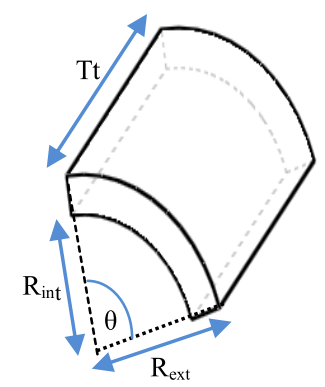

Fig. 4. Geometrical view of leakage flux tube.
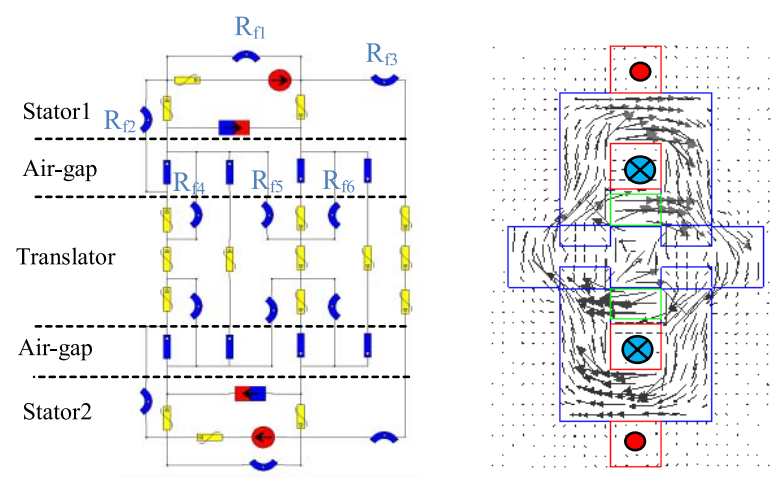

Fig. 5. RN model and finite element model of 1/4 LHM.

is modeled by a magnetic reluctance given by the following expression:

$$
\Re_{f}=\frac{\theta}{\mu_{0} \cdot \mathrm{Tt}} \frac{1}{\ln \left(\frac{R_{\mathrm{ex}}}{R_{\mathrm{in}}}\right)}
$$

where $\theta$ is the angle of the circumferences arc. $R_{\mathrm{ex}}$ and $R_{\text {in }}$ are, respectively, the exterior radius and interior radius of the circumferences arc, as shown in Fig. 4.

Each part of the flux leakage is modeled by an adapted magnetic reluctance. The parameters of the magnetic reluctances are parameterized with the displacement of the mobile part. Indeed, the flux path of each part increases or decreases with the displacement of the mobile part. In this RN model, the leakage flux reluctances change according the translator displacement. The RN is modeled in the software Reluctool, and the finite element model of $1 / 4$ LHM is shown in Fig. 5.

When the translator is moved from the unaligned position to the aligned position, the flux modeled using the reluctance $\Re_{f 2}$ decreased considerably. The angle formed is equal to $1.57 \mathrm{rad}$. The interior radius is constant and equal to the half of the air gap. However, the exterior radius decreases according the expression $\mathrm{Tw}-x$. The $\Re_{f 2}$ is given by the following expression:

$$
\Re_{f 2}=\frac{1,57}{\mu_{0} \cdot \mathrm{Tt}} \frac{1}{\ln \left(\frac{\mathrm{Tw}-x}{e / 2}\right)} .
$$

The exterior radius of the flux modeled using $\Re_{f 4}$ decreases according the expression $(\mathrm{Tw}-x) / 2$. Indeed, in the unaligned position, the exterior radius is equal to the half of the tooth width. Applying, the same methodology, all of flux leakage reluctances is determined. The $\Re_{f 3}$ and $\Re_{f 5}$ are, respectively,

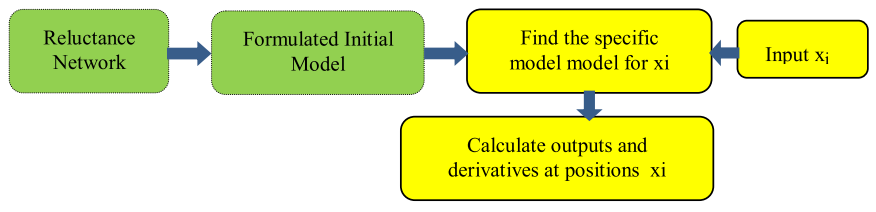

Fig. 6. RN model algorithm.

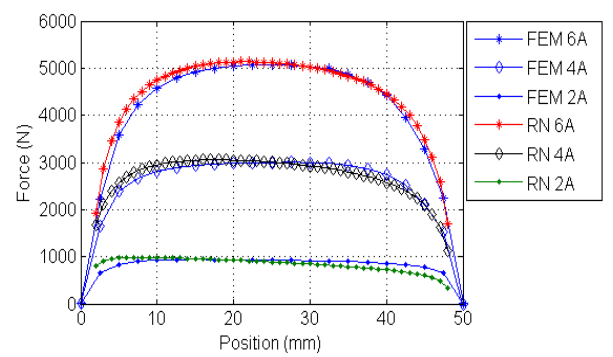

Fig. 7. Propulsive forces calculated with FEM and RN model.

given as

$$
\begin{aligned}
\Re_{f 3} & =\frac{1,57}{\mu_{0} \cdot \mathrm{Tt}} \frac{1}{\ln \left(\frac{\mathrm{Tw}}{e / 2+x}\right)} \\
\Re_{f 5} & =\frac{1,57}{\mu_{0} \cdot \mathrm{Tt}} \frac{1}{\ln \left(\frac{\mathrm{Tw} / 2}{e / 2+x / 2}\right)} .
\end{aligned}
$$

The $\Re_{f 4}$ and $\Re_{f 6}$ are written as

$$
\Re_{f 4}=\Re_{f 6}=\frac{1,57}{\mu_{0} \cdot \mathrm{Tt}} \frac{1}{\ln \left(\frac{(\mathrm{Tw}-x) / 2}{e / 2}\right)} .
$$

The reluctance $\Re_{f 1}$ represents the flux leakage canalized between the two poles in the same stator. The flux leakage in this case is constant. The angle formed is 3,14 rad. Consequently, $\Re_{f 1}$ is given as

$$
\Re_{f 1}=\frac{3,14}{\mu_{0} \cdot \mathrm{Tt}} \frac{1}{\ln \left(\frac{1,5 \cdot \mathrm{Tw}}{e / 2}\right)} .
$$

\section{STATIC FORCES COMPARISON}

The algorithm that solves the RN is shown in Fig. 6 . It allows reducing the computation time. A set of mobile part positions has to be defined before generating the model.

The propulsive forces calculated with RN model implemented by the Reluctool software and the FEM for three different current excitations are shown in Fig. 7. As shown earlier, force curves are almost identical. Hence, the RN model of the LHM is in accordance with the FEM.

\section{LHM OPTIMIZATION}

The objective function of this optimization consists in minimizing the LHM mass while keeping the propulsive force. Moreover, the LHM mass is a very important parameter in the level of actuator manufacturing and transportation. However, many constraints must be respected. In particular, the propulsive force must be kept greater than $5000 \mathrm{~N}$. The optimization constraints are summarized in Table II.

The RN model proposed in this paper reduces the computation time in both modeling and optimization of the LHM. 
TABLE II

OPTIMIZATION CONSTRAINTS

\begin{tabular}{lll}
\hline \hline \multicolumn{1}{c}{ Quantity } & \multicolumn{1}{c}{ Minimum Value } & Maximal Value \\
\hline Tooth width (Tw) & $34 \mathrm{~mm}$ & $60 \mathrm{~mm}$ \\
Slot width (Sw) & $34 \mathrm{~mm}$ & $60 \mathrm{~mm}$ \\
Permanent magnet width (PMw) & $30 \mathrm{~mm}$ & $50 \mathrm{~mm}$ \\
Slot depth (Sd) & $30 \mathrm{~mm}$ & $100 \mathrm{~mm}$ \\
Translator thickness (Tt) & $100 \mathrm{~mm}$ & $300 \mathrm{~mm}$ \\
Translator pole length (Tpl) & $20 \mathrm{~mm}$ & $100 \mathrm{~mm}$ \\
Translator cylinder head (Tch) & $1 \mathrm{~mm}$ & $30 \mathrm{~mm}$ \\
Turns per phase (N) & 1 & $2000 \mathrm{~mm}$ \\
Maximum propulsive force & $5000 \mathrm{~N}$ & $6000 \mathrm{~N}$ \\
\hline \hline
\end{tabular}

TABLE III

Optimization Results of GeOMETRICAL PARAMETERS

\begin{tabular}{lll}
\hline \hline \multicolumn{1}{c}{ Quantity } & \multicolumn{1}{c}{ Initial Value } & Optimal Value \\
\hline Tooth width $(\mathrm{mm})$ & 50 & 34 \\
Slot width $(\mathrm{mm})$ & 50 & 34 \\
Phase separation $(\mathrm{mm})$ & 25 & 17 \\
Slot depth $(\mathrm{mm})$ & 50 & 59,76 \\
Translator thickness $(\mathrm{mm})$ & 200 & 282,31 \\
Translator pole length $(\mathrm{mm})$ & 20 & 20 \\
Translator cylinder head $(\mathrm{mm})$ & 20 & 1 \\
Turns per phase $(\mathrm{mm})$ & 1500 & 1193 \\
\hline \hline
\end{tabular}
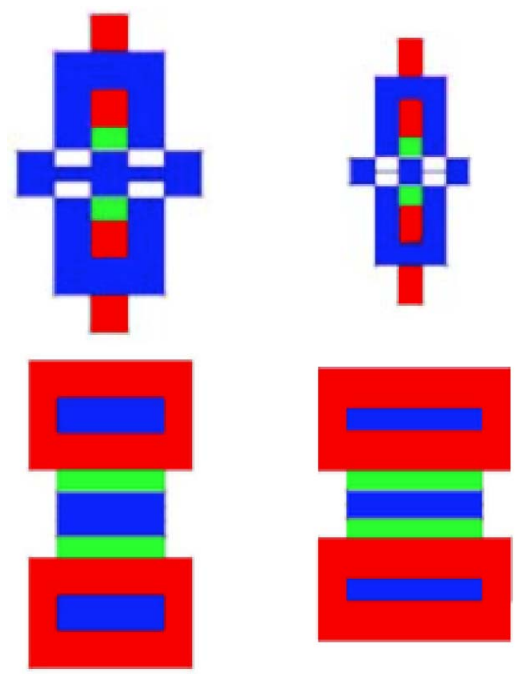

Initial geometry

Optimized geometry

Fig. 8. Initial and optimized LHM geometry.

The optimization process ends in $3463 \mathrm{~ms}$ after 28 iterations. The initial and optimal geometrical and electrical parameters are given in Table III.

The initial and optimized geometrical structures are shown in Fig. 8.

The mass of different parts of the initial and optimized structures is summarized in Table IV. The maximum propulsive force is also given in the same table.

The propulsive force of the optimized structure is calculated using two methods: 1) the RN model and 2) the FEM. The obtained results are shown in Fig. 9, which confirms the robustness of the developed RN model.

TABLE IV

Optimization Results of MAss AND PROPUlsive Force

\begin{tabular}{lll}
\hline \hline \multicolumn{1}{c}{ Quantity } & \multicolumn{1}{c}{ Initial Value } & Optimal Value \\
\hline Stator mass $(\mathrm{kg})$ & 193,44 & 168,62 \\
Translator mass $(\mathrm{kg})$ & 65,52 & 34,44 \\
Permanent magnet mass $(\mathrm{kg})$ & 18,24 & 17,50 \\
Winding mass $(\mathrm{kg})$ & 87,98 & 87,14 \\
Total mass $(\mathrm{kg})$ & 365,18 & 307,71 \\
Maximum propulsive Force (N) & 5051,52 & 5250,22 \\
\hline
\end{tabular}

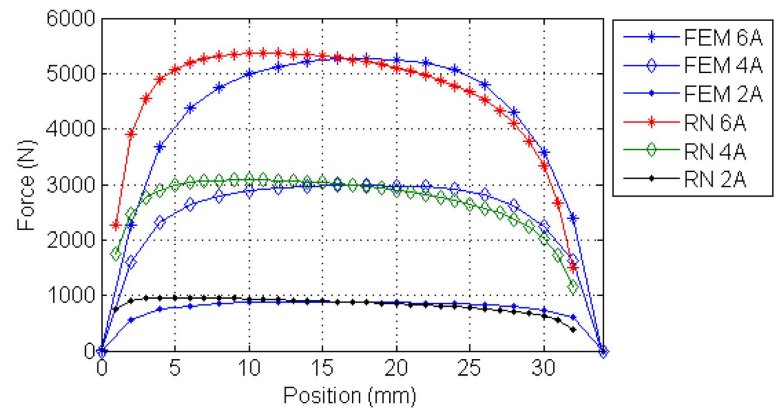

Fig. 9. Static force of the optimal structure calculated with FEM and RN.

\section{CONCLUSion}

A precise $\mathrm{RN}$ model is developed to model, design, and optimize a linear actuator. This model is developed using the Reluctool software and is validated using the FEM. The efficiency of this model is its ability to generate automatically the electromagnetic characteristics for any mobile part positions. This model has a good numerical stability and leads to precise force computation. The model is applied for sizing by optimization. The sequential quadrating programming method is used, and accurate optimization results are obtained. The simulation results presented and discussed confirm the robustness of the developed $\mathrm{RN}$ model and the optimization approach.

\section{ACKNOWLEDGMENT}

This work is supported by University of Tunis El Manar (Tunisia), Univ. Grenoble Alpes, G2Elab (France), and Almajmaah University (Saudi Arabia).

\section{REFERENCES}

[1] R. Krishnan, Switched Reluctance Motor Drives: Modeling, Simulation, Analysis, Design, and Applications. Boca Raton, FL, USA: CRC Press, 2001.

[2] L. Szabó, I. A. Viorel, I. Chişu, and Z. Kovács, "A novel double salient permanent magnet linear motor," in Proc. Int. Conf. Power Electron. Drives Motion (PCIM), 1999, pp. 285-290.

[3] B. du Peloux, L. Gerbaud, F. Wurtz, V. Leconte, and F. Dorschner, "Automatic generation of sizing static models based on reluctance networks for the optimization of electromagnetic devices," IEEE Trans. Magn., vol. 42, no. 4, pp. 715-718, Apr. 2006.

[4] T. Raminosoa, I. Rasoanarivo, F. Meibody-Tabar, and F. M. Sargos, "Time-stepping simulation of synchronous reluctance motors using a nonlinear reluctance network method," IEEE Trans. Magn., vol. 44, no. 12 , pp. $4618-4625$, Dec. 2008.

[5] H. Nguyen-Xuan, H. Dogan, S. Perez, L. Gerbaud, L. Garbuio, and F. Wurtz, "Efficient reluctance network formulation for electrical machine design using optimization," IEEE Trans. Magn., vol. 50, no. 2, Feb. 2014, Art. ID 7021504. 